\title{
2019 Year in Review: Patient-Ventilator Synchrony
}

\author{
Robert L Chatburn and Eduardo Mireles-Cabodevila
}

\author{
Introduction \\ A Note About Nomenclature \\ Brief Historical Perspective \\ Year in Review \\ Literature Reviews \\ Manual Detection of Synchrony Problems \\ Automated Detection of Synchrony Problems \\ Modes for Improving Synchrony \\ Effects of Sedation \\ Toward a Taxonomy for Patient-Ventilator Synchrony \\ Summary
}

\begin{abstract}
Patient-ventilator synchrony is a popular topic of research on mechanical ventilation. This review puts this research into both contemporary and historical perspective. Five areas of research are described: literature reviews, manual detection of synchrony problems, automated detection of synchrony problems, modes for improving synchrony, and effects of sedation. We note that this type of research lacks a standardized vocabulary and associated taxonomy, which generates difficulty in communication among students and researchers, as well as in comparison of results. Hence, we conclude this paper with some suggestions for improvement in that regard. [Respir Care 2020;65(4):558-572. C 2020 Daedalus Enterprises]
\end{abstract}

\section{Introduction}

Although there are any number of indications for the initiation of mechanical ventilation, there are only 3 basic

Mr Chatburn and Dr Mireles-Cabodevila are affiliated with Lerner College of Medicine, Case Western Reserve University, Cleveland, Ohio. Mr Chatburn and Dr Mireles-Cabodevila are affiliated with the Respiratory Institute, Cleveland Clinic, Cleveland, Ohio. $\mathrm{Mr}$ Chatburn and Dr Mireles-Cabodevila are affiliated with the Education Institute, Cleveland Clinic, Cleveland, Ohio.

Mr Chatburn has disclosed relationships with IngMar Medical and Vyaire Medical. Dr Mireles-Cabodevila has disclosed no conflicts of interest.

Correspondence: Robert Chatburn MHHS RRT-NPS FAARC, Cleveland Clinic, Respiratory Therapy T03-35, 9500 Euclid Ave, Cleveland, OH 44121. E-mail: chatbur@ccf.org.

DOI: $10.4187 /$ respcare. 07635 goals after initiation: safety (ie, adequate gas exchange with avoidance of ventilator-induced lung injury), comfort (ie, optimum patient-ventilator synchrony with adequate support for the work of breathing), and liberation (ie, the shortest possible duration of ventilation with avoidance of adverse events). Arguably, the goal of safety is the subject of the most intensive current research; although patient-ventilator synchrony is a popular research topic, we are still not certain whether synchrony problems have a causative or associative relationship to overall patient outcomes. ${ }^{1,2}$ Synchrony problems are common, occurring in perhaps as many as $25 \%$ of patients receiving invasive ventilation and up to $80 \%$ of patients receiving noninvasive ventilation. ${ }^{2}$

\section{A Note About Nomenclature}

The nomenclature describing abnormal patient-ventilator synchrony is not consistent in the literature. For now, we 


\section{Patient-Ventilator Synchrony}

Table 1. Taxonomy for Discordant Patient-Ventilator Interactions

\begin{tabular}{|c|c|c|c|}
\hline & Alternative Name & Definition & Cause \\
\hline \multicolumn{4}{|l|}{ Asynchrony } \\
\hline False trigger & $\begin{array}{l}\text { Auto-triggering, double- } \\
\text { triggering, multiple- } \\
\text { triggering }\end{array}$ & Triggering by a signal other than $P_{\text {mus }}$ & $\begin{array}{l}\text { Trigger threshold set too low (ie, high sensitivity), } \\
\text { or circuit leak, secretions, cardiac oscillations, } \\
\text { water in circuit, etc. }\end{array}$ \\
\hline Failed trigger & $\begin{array}{l}\text { Ineffective effort, } \\
\text { missed trigger }\end{array}$ & Patient trigger signal fails to start $P_{v e n t}$ & $\begin{array}{l}\text { Trigger threshold set too high (ie, low sensitivity) or } \\
\text { autoPEEP higher than } \mathrm{P}_{\mathrm{mus}}\end{array}$ \\
\hline \multicolumn{4}{|l|}{ Dyssynchrony } \\
\hline Early trigger & Reverse-triggering & $P_{\text {vent }}$ starts before $P_{\text {mus }}$ (or surrogate) & Sedation, brain injury, pleural irritation \\
\hline Late trigger & Delayed triggering & $\begin{array}{l}\text { Clinically important delay in start of } \\
P_{\text {vent }} \text { after } P_{\text {mus }} \text { (or surrogate) }\end{array}$ & $\begin{array}{l}\text { Trigger threshold set too high (ie, low sensitivity) or } \\
\text { slow ventilator response time }\end{array}$ \\
\hline Early cycling & Premature cycling & $\begin{array}{l}\text { Clinically important advance in } \mathrm{P}_{\text {vent }} \\
\text { return to baseline before } \mathrm{P}_{\text {mus }} \text { return } \\
\text { to baseline }\end{array}$ & $\begin{array}{l}\text { Neural inspiratory time longer than waveform } \\
\text { inspiratory time; flow cycle threshold set too high } \\
\text { or inspiratory time set too short; may be clinically } \\
\text { appropriate }\end{array}$ \\
\hline Late cycling & $\begin{array}{l}\text { Delayed cycle, runaway } \\
\text { phenomena }\end{array}$ & $\begin{array}{l}\text { Clinically important delay in } \mathrm{P}_{\text {vent }} \\
\text { return to baseline after } \mathrm{P}_{\text {mus }} \text { return to } \\
\text { baseline }\end{array}$ & $\begin{array}{l}\text { Neural inspiratory time shorter than waveform } \\
\text { inspiratory time; flow cycle threshold set too low } \\
\text { or inspiratory time set too long; may be clinically } \\
\text { appropriate }\end{array}$ \\
\hline False cycle & None & $\begin{array}{l}P_{\text {vent }} \text { return to baseline due to a signal } \\
\text { other than } P_{\text {mus }}\end{array}$ & $\begin{array}{l}\text { Pressure over-shoot activating alarm (eg, pressure } \\
\text { rise time set too short) }\end{array}$ \\
\hline \multicolumn{4}{|l|}{ Work balance } \\
\hline Work shifting & Flow starvation & $\begin{array}{l}\text { Decrease in } \mathrm{P}_{\text {vent }} \text { with constant tidal } \\
\text { volume or increase in tidal volume } \\
\text { with constant } \mathrm{P}_{\text {vent }} \text { resulting in } \\
\text { increased patient work relative to } \\
\text { total inspiratory work }\end{array}$ & $\begin{array}{l}\text { High inspiratory effort due to anxiety, pain, acidosis; } \\
\text { may be clinically appropriate }\end{array}$ \\
\hline Expiratory work & None & $\begin{array}{l}\text { Increase in tidal volume above passive } \\
\text { expiration }\end{array}$ & $\begin{array}{l}\text { Nonpassive expiration due to anxiety, acidosis, pain, } \\
\text { bronchospasm, or cough }\end{array}$ \\
\hline \multicolumn{4}{|c|}{$\begin{array}{l}\mathrm{P}_{\text {vent }}=\text { ventilator pressure associated with inspiratory flow } \\
\mathrm{P}_{\text {mus }}=\text { muscle pressure due to inspiratory effort } \\
\text { Trigger = start of inspiratory flow from ventilator } \\
\text { Cycle = start of expiratory flow from ventilator }\end{array}$} \\
\hline
\end{tabular}

will use the terminology used by the authors in the cited papers without giving their definitions. We do this to avoid any misinterpretation of the authors' work and to give the reader an appreciation for the variance in the terms used. We will address the issue of a taxonomy based on a standardized vocabulary at the end of this review. We offer a tentative list of definitions for synchrony problems in Table $1 .^{3}$ Note that all mechanical patientventilator interactions can (and should) be described in terms of the parameters and variables in the equation of motion (described in the next section) and in reference to the patient signal.

\section{Brief Historical Perspective}

Some landmark articles in the development of the concept of patient-ventilator synchrony problems are summarized here to provide some context to the current articles that comprise the main section of this review.
In 1995, Fabry et $\mathrm{al}^{4}$ reported that desynchronization during ventilation with pressure support (identified using esophageal pressure as a reference signal) may be due to (1) inspiratory response delays caused by the inspiratory triggering mechanisms and the demand flow characteristics of the ventilator; (2) a mismatch between the patient's completion of the inspiration effort and the ventilator's criterion for terminating pressure support; and (3) restriction of expiration due to resistance from patient's airways, endotracheal tube, and expiratory valve.

In 1985, Marini et $\mathrm{al}^{5}$ were the first to report that, during volume control ventilation, work performed by the subject increased substantially when flow from the machine was insufficient to meet demand-what we now call work shifting. Later, in 1997, MacIntyre et $\mathrm{al}^{6}$ were probably the first to use the term patient-ventilator flow asynchrony and to offer the suggestion that asynchrony can be improved by increasing ventilator flow delivery. These authors also noted that pressure control modes would be a better 


\section{Patient-Ventilator Synchrony}

approach for matching patient flow demands than volume control modes.

In 1989, Flick et $\mathrm{al}^{7}$ noted that during "breaths initiated by the ventilator, there is no electromyographic activity present except when the delivered tidal volume approaches the patient's spontaneous tidal volume. At low tidal volumes, controlled breaths are assisted late in the breath." In a 2005 study, Kallet et $\mathrm{al}^{8}$ also reported this observation and clarified the concept by saying, "In several cases, spontaneous breathing during (volume control ventilation) was stimulated by the ventilator, and patient effort commenced only toward the end of the mechanical breath ...." Much later, in 2013, Akoumianaki et $\mathrm{al}^{9}$ described this phenomenon in detail and gave it the name reverse-triggered breaths. In 1997, Chao et al ${ }^{10}$ described trigger asynchrony during prolonged ventilation with volume control (identified with esophageal pressure as a reference signal) and noted that it was associated with poor outcomes.

In 2003, Kondili et $\mathrm{al}^{11}$ first described patient-ventilator synchrony problems in terms of the equation of motion. There are many forms of the equation, and these authors used $\mathrm{P}_{\text {mus }}+\mathrm{P}_{\text {vent }}=\left(\mathrm{E}_{\mathrm{rs}} \times \mathrm{V}\right)+\left(\mathrm{R}_{\mathrm{rs}} \times \dot{\mathrm{V}}\right)$, where $\mathrm{P}_{\text {mus }}$ is the muscle pressure generated by the patient's inspiratory effort, $\mathrm{P}_{\mathrm{vent}}$ is the airway pressure relative to PEEP generated by the ventilator, $\mathrm{E}_{\mathrm{rs}}$ is the elastance of the respiratory system, $\mathrm{V}$ is the volume change relative to end-expiratory lung volume, $\mathrm{R}_{\mathrm{rs}}$ is the resistance of the respiratory system and artificial airway, and $\dot{V}$ is the flow (positive is inspiration, negative is expiration). This equation makes explicit the concept that there are two "pumps" that must function in harmony, ie, the ventilatory muscles $\left(\mathrm{P}_{\text {mus }}\right)$ and the ventilator $\left(\mathrm{P}_{\mathrm{vent}}\right)$. These authors point out that harmony depends on the physician, suggesting that the ventilator should match the patient's demands, rather than forcing the patient to conform to ventilator performance.

Continuing the work of Kondili et al, ${ }^{11}$ in 2006 Georgopoulous et $\mathrm{al}^{12}$ were the first to provide a theoretical framework for interpreting ventilator waveforms based on several different versions of the equation of motion. This work emphasizes that ventilator waveforms are simply graphical representations of the equation of motion. Understanding the theory makes explaining virtually every patient-ventilator interaction much more logically consistent.

Also in 2006, Thille et $\mathrm{al}^{13}$ were the first to describe an asynchrony index, defined as the number of asynchrony events divided by the total breathing frequency computed as the sum of the number of ventilator cycles (patient-triggered or not) and wasted efforts: asynchrony index = number of asynchrony events/total breathing frequency (ventilator cycles + wasted efforts) $\times 100$ (expressed as a percentage). They also defined a "high" incidence of asynchrony as an asynchrony index $>10 \%$.
In 2007, Younes et $\mathrm{al}^{14}$ reported on Younes' invention of the mode called proportional assist ventilation. ${ }^{15}$ As a spinoff of this technology, Younes also invented a patientventilator interaction monitor that was never commercialized. In 2010, Kondili et a ${ }^{16}$ gave detailed descriptions of the monitor's performance in terms of actually measuring $\mathrm{P}_{\text {mus. }}$

In 2007 and 2009, Mulqueeny and colleagues ${ }^{17,18}$ reported the first automated system for detecting ineffective trigger efforts. Compared to human experts, the system achieved a 95\% overall accuracy rate. In 2013, Sinderby et al ${ }^{19}$ described a sophisticated, automated, standardized system to report what they called the NeuroSync Index, based on the electrical activity of the diaphragm $\left(\mathrm{EA}_{\mathrm{di}}\right)$ signal from a ventilator equipped to deliver neurally-adjusted ventilatory assist (NAVA). The system provides real-time detection and quantification of ineffective triggering, double-triggering, auto-triggering, early cycling, and delayed cycling. These authors were the first to emphasize the utility of discriminating between dyssynchony (ie, ventilator out of phase with a reference signal, eg, $\mathrm{EA}_{\mathrm{di}}$ ) and asynchrony (ie, one signal missing).

\section{Year in Review}

The articles reviewed here are all those published on the topic in 2019, with some from 2018 if they are of particular interest. They are grouped according to topic: literature reviews, manual detection of synchrony problems, automated detection of synchrony problems, modes for improving synchrony, effects of sedation, and the taxonomy of patient-ventilator synchrony.

\section{Literature Reviews}

Bruni et $\mathrm{al}^{2}$ conducted a review of all studies published on patient-ventilator synchrony in the last 25 years. They reviewed 62 studies overall, which included 1,747 subjects. They noted that $75 \%$ of the studies reported only major asynchronies (ie, ineffective triggering or wasted efforts, auto-triggering, and double-triggering), while $42 \%$ also reported minor asynchronies (ie, premature cycling and prolonged or delayed cycling). As we will see, this is an incomplete list of synchrony problems. These authors included pressure, flow, and $\mathrm{EA}_{\mathrm{di}}$ waveforms for representative examples of ineffective triggering, auto-triggering, double-triggering, premature cycling, and delayed cycling. Ineffective triggering was reported in $92 \%$ of the studies, and the most common causes of ineffective triggering were (1) weak inspiratory effort secondary to heavy sedation, excessive ventilatory support, or diaphragm dysfunction; (2) high intrinsic PEEP; or (3) an excessively low trigger sensitivity. Auto-triggering was reported in $73 \%$ of the studies, with reported mechanisms of (1) cardiac oscillations, (2) air 


\section{Patient-Ventilator Synchrony}

leaks, (3) water in the ventilator circuit causing pressure or flow oscillations, (4) copious airway secretions, and (5) high trigger sensitivity. Double-triggering was reported in $73 \%$ of the studies, with the following possible mechanisms: (1) a high respiratory drive or (2) a low respiratory system compliance causing premature cycling during ventilation with pressure support with a high flow cycle threshold. Minor asynchronies were reported in $42 \%$ of the studies, but methods for detecting synchrony problems were not consistent among studies. Three categories were described. First, clinical detection was the most common method reported (39\% of studies), and this involved visual inspection of pressure and flow waveforms displayed by the ventilator. Second was the detection of adjunctive signals, such as $\mathrm{EA}_{\mathrm{di}}$ (used in $73 \%$ of the studies), esophageal pressure (used in $15 \%$ of the studies), and transdiaphragmatic pressure ( $12 \%$ of the studies). The third category was the detection by automated algorithms, as proposed by $8 \%$ of the studies; such methods included analysis of the expiratory flow waveform to detect ineffective inspiratory efforts. A more sophisticated method, described by Younes et al,${ }^{14}$ calculates a real-time signal representing ventilatory $\mathrm{P}_{\text {mus. }}$. Mulqueeny et $\mathrm{al}^{17}$ described a system that could detect both ineffective triggering and double-triggering. Gutierrez et $\mathrm{al}^{20}$ applied spectral analysis (ie, fast Fourier transform) to the air-flow signal during the expiratory phase to calculate the asynchrony index, which is defined as the number of asynchrony events divided by the total breathing frequency (computed as the sum of the number of ventilator cycles, triggered or not, and of wasted efforts), as proposed by Thille et al. ${ }^{13}$ This asynchrony index was used in $65 \%$ of the studies, although there was no consistency in how the index was calculated. The ineffective trigger index, calculated by dividing the number of ineffectively triggered breaths by the total number of breaths, both triggered and ineffectively triggered, ${ }^{21}$ was mentioned in $8 \%$ of the studies. A relationship between patient-ventilator asynchrony and one or more clinical outcomes was reported in $26 \%$ of the studies. Outcomes included weaning success, duration of mechanical ventilation, sleep quality, and comfort. However, a shortage of randomized controlled trials, inconsistency in reporting the rate of asynchronies, heterogeneity of outcomes measured, and a low number of enrolled subjects prevented pooled data analysis. The authors concluded, somewhat surprisingly, that "definition and classification of patient-ventilator asynchronies are quite standardized. Conversely, the indexes for quantification of asynchronies are various and unevenly calculated." ${ }^{2}$ They suggest that future studies be designed to ascertain unequivocally whether the relationship between asynchrony and worsened outcomes is causative or just associative.

The review article by de Haro et $\mathrm{al}^{22}$ aimed to summarize what is known about patient-ventilator interaction and asynchronies in mechanical ventilation, to show its effects on outcomes, and to describe new directions in research about these questions. They also provided representative pressure, volume, and flow waveforms to illustrate ineffective trigger efforts, double-cycling, reverse-triggering, and inspiratory flow asynchrony. They explained that patientventilator asynchrony occurs when there is a mismatch between ventilator assistance and patient demand, noting the classification system based on this idea by Pham et al. ${ }^{23}$ This paper goes into great detail about the physiologic consequences of the listed asynchronies and, in particular, about reverse-triggering. There is also a comprehensive section on heart-lung interaction in patients with asynchronies, giving details of how they affect preload and afterload. In a section on how asynchronies affect patient outcomes, the authors cited references indicating worse prognosis, increased need for sedation, prolongation of mechanical ventilation, increased ICU and hospital length of stays, and increased mortality. The authors reviewed many studies that provide some data that asynchronies affect outcomes. Their review of neuropsychological outcomes is particularly interesting. Nevertheless, they cautioned that a causal relation between patient-ventilator synchrony problems and worse outcomes has yet to be convincingly demonstrated. They suggested that to determine such a causal relationship, future studies must identify and quantify asynchronies throughout the entire period of mechanical ventilation. In this regard, the authors pointed out that ventilated patients generate huge amounts of data (eg, 173 million data points per day, and as many as 1 billion over the average duration of ventilation), yet most of these data are never used. As a result, they stated that most physicians perform poorly when it comes to managing patient-ventilator interactions, and even the most highly skilled clinicians can observe only a small portion of the available data. This situation motivates the desire to develop artificial intelligence tools to mine the big data and provide automated asynchrony detection. This paper provides a unique table that compares some automated methods described in the literature, showing the type of asynchronies detected, the algorithms used, and accuracy specifications. They also describe emerging systems that use big data solutions to support daily clinical decision making and improve patient care.

Holanda et $\mathrm{al}^{24}$ provide a more comprehensive description of different asynchronies including ineffective triggering, double-triggering, reverse-triggering, auto-triggering, premature cycling, delayed cycling, insufficient flow, and excessive flow. They illustrate them with pressure, volume, and flow waveforms generated by a subscription-based online patient-ventilator simulator (https://xlung.net/en, Accessed February 14, 2020). We believe this is a much more useful approach than using ventilator waveforms because the ventilatory $\mathrm{P}_{\text {mus }}$ waveform, which is the reference signal for defining asynchrony, can be shown along 


\section{Patient-Ventilator SynChrony}

with airway pressure, volume, and flow waveforms. $\mathrm{EA}_{\mathrm{di}}$ and esophageal pressure signals are difficult to simulate. At Cleveland Clinic, we developed a free simulator that can be used to generate similar waveforms (https://app.box.com/s/ djt9adrbqlkz98qaiodt1jzxus8vrjur, Accessed February 14, 2020). An even better approach is to use a physical simulator (eg, IngMar ASL 5000 breathing simulator or Hans Rudolph series 1101 Breathing Simulator) connected to a real ventilator. In this regard, it is important to select realistic simulation parameters. $^{25}$

Garofalo et $\mathrm{al}^{1}$ give a review of patient-ventilator asynchronies and how they are detected, quantified, and classified. They include ineffective effort, auto-triggering, double-triggering, premature cycling, delayed cycling, and triggering delay, and they provided pressure, flow, and $\mathrm{EA}_{\mathrm{di}}$ signals to illustrate these asynchronies. This paper is unique in that it has separate sections for adult and neonatal/pediatric papers under broader categories of invasive and noninvasive ventilation (NIV). ${ }^{1}$ Unlike the papers mentioned above, this paper has a detailed section on managing patient-ventilator asynchrony. The authors concluded that clinically relevant asynchronies are common both in invasive ventilation and NIV and are observed not only in adults but also in pediatric subjects and in long-term treatment for chronic respiratory failure. Furthermore, detection of asynchronies is problematic, and software for automated detection and use of adjunctive signals such as $\mathrm{EA}_{\mathrm{di}}$ and esophageal pressure is helpful. Patient-ventilator synchrony can be improved with proper adjustment of ventilator settings, cautious administration of sedatives, and use of modes with that provide continuous spontaneous ventilation with servo targeting (ie, inspiratory pressure proportional to inspiratory effort ${ }^{26,27}$ ). As other authors have done, they assert that high rates of asynchrony are associated with worse outcomes, but causation has yet to be demonstrated. ${ }^{1}$

A paper by Bulleri et $\mathrm{al}^{28}$ is the only one we have seen that is directed at nurses. The aims of the paper were to identify asynchronies, to describe how they affect patient outcomes, and, notably, to investigate the levels of nursing skill in detecting them. The asynchronies included were ineffective effort and trigger delay, premature cycling and double-triggering, auto-triggering, reverse-triggering, delayed cycling, and flow starvation. These were illustrated with pressure, flow, and $\mathrm{EA}_{\mathrm{di}}$ waveforms. The authors noted that published studies about nurses' knowledge and skills in ventilator graphic interpretation are scarce (they found only 4). ${ }^{28}$ One paper reported that nurses, if adequately trained, can detect patients' ineffective efforts with the same accuracy as expert clinicians; a second paper indicated that nurses retained knowledge about ventilator graphics interpretation 6 months after training; the third paper evaluated the effects of education of nurses and respiratory therapists, and results showed an increase in knowledge but failed to demonstrate a reduction of ventilation duration. ${ }^{28}$

\section{Manual Detection of Synchrony Problems}

Akoumianaki et $\mathrm{al}^{9}$ in 2013 were the first to report reverse-triggering in adult subjects. In 2019, Blokpoel et $\mathrm{al}^{29}$ reported the phenomenon in a mechanically ventilated 11-month-old infant. Sedation was managed with propofol targeting a COMFORT behavior scale of $10 .{ }^{30}$ They provided a set of waveforms showing airway pressure and flow along with $\mathrm{EA}_{\mathrm{di}}$, intercostal muscle, and abdominal electromyography signals. $^{29}$

In a letter published in a 2019 issue of Intensive Care Medicine, Su et $\mathrm{al}^{31}$ described a method of identifying reverse-triggering using the Campbell diagram based on esophageal pressure. Of 56 subjects, 17 (30\%) exhibited reverse-triggering. Reverse-triggering was observed in 171 of 3,849 breaths (4\%) over $145 \mathrm{~min}$ of recording. Diaphragmatic contraction started in late inspiration for $41 \%$ of instances and in early expiration in 59\%. Reversetriggering resulted in significantly larger tidal volumes (593 mL vs $414 \mathrm{~mL}$, but the mode of ventilation was not stated). Maximum transpulmonary pressure fluctuation was $23 \mathrm{~cm} \mathrm{H}_{2} \mathrm{O}$. The authors noted that, although reverse-triggering may contribute to ventilator-initiated lung injury, ${ }^{32}$ it may also act as a miniature recruitment maneuver.

Soilemezi et $\mathrm{al}^{33}$ described a method of understanding patient-ventilator asynchrony using diaphragmatic ultrasonograpy. They observed a striking concordance of esophageal pressure and M-mode diaphragmatic displacement tracings. They believe this provides a rationale for using diaphragmatic motion sonography to assess patient-ventilator asynchrony. ${ }^{34}$ The article illustrates double-triggering, ineffective efforts, and reverse-triggering. The authors noted that the major limitation of this technique is the inability to perform continuous monitoring.

\section{Automated Detection of Synchrony Problems}

Most of the articles reviewed on automated detection of synchrony problems were published in 2018. Sottile et $\mathrm{al}^{35}$ conducted a single-center prospective study and developed an accurate computerized algorithm to detect ventilator asynchrony. They sought to determine whether asynchrony, as detected with this algorithm, was associated with large tidal volumes and whether this asynchrony improved with deeper sedation or the use of neuromuscular blockade. Subjects were admitted to a medical ICU at risk for or with ARDS and requiring mechanical ventilation. Continuous ventilator data (ie, pressure, flow, and volume measurements along with mode and settings) were collected using a laptop computer connected to the ventilator and using 


\section{Patient-Ventilator Synchrony}

Hamilton DataLogger 5.0 software. The modes used were pressure control continuous mandatory ventilation with either set-point or adaptive targeting. ${ }^{26}$ Data were collected until extubation or for up to $7 \mathrm{~d}$ per subject. The algorithm for detecting ventilator asynchrony was developed using Python and the SciPy scientific stack, an open-source programing and scientific analysis toolset with machine learning and validation features. The algorithm was designed to detect double-triggered, flow-limited, premature ventilatorterminated, or ineffective-triggered breaths, although these were not specifically defined. The term flow-limited is particularly puzzling; it suggests volume control (ie, pre-set tidal volume and inspiratory flow), but the data were recorded only during pressure control ventilation. From a cohort of 62 subjects, 4.26 million breaths were recorded. The performance of the algorithm was analyzed with receiver operating characteristic curve (ROC) analysis. Double-triggered, flow-limited, and synchronous breaths demonstrated an ROC of $>89 \%$, whereas ineffective triggered breaths had an ROC of $91 \%$. Premature ventilatorterminated breaths could not be accurately assessed. For subjects not on neuromuscular blockade agents, 34\% of breaths were dyssynchronous. When analyzed by subject, the median percentage of dyssynchronous breaths was $47 \%$, and all subjects had some dyssynchronous breaths. By type of ventilator asynchrony, 29\% were premature ventilator-terminated breaths, $25 \%$ were ineffective triggered breaths, $14 \%$ were flow-limited breaths, and $3 \%$ were double-triggered breaths; the authors noted that different types were not mutually exclusive. Despite the use of adaptive targeting with a tidal volume target averaging $6 \mathrm{~mL} / \mathrm{kg}$, double-triggered and flow-limited breaths were consistently associated with larger mean delivered tidal volumes (12 $\mathrm{mL} / \mathrm{kg}$ ) compared to synchronous breaths. Despite the use of low tidal volume ventilation, $>10 \%$ of all breaths recorded were associated with ventilator asynchrony and resulted in tidal volumes $>10 \mathrm{~mL} / \mathrm{kg}$. Deep sedation reduced but did not eliminate the frequency of all breaths showing ventilator asynchrony.

Gholami et $\mathrm{al}^{36}$ addressed the issue of how to replicate human expertise of waveform analysis for detecting cycling asynchrony (ie, delayed termination, premature termination, or none). They described a pilot study involving 11 invasively ventilated subjects in the ICU. A machine-learning algorithm was used to detect cycling asynchrony based on waveform analysis. A panel of 5 experts with experience in patient-ventilator asynchrony examined 1,377 breaths from 11 subjects. They labeled each breath according to cycling asynchrony type. The algorithm accurately detected the presence or absence of cycling asynchrony with sensitivity (specificity) of $89 \%$ (99\%), 94\% (98\%), and 97\% (93\%) for delayed termination, premature termination, and no cycling asynchrony, respectively. The system showed strong agreement with human experts as reflected by the kappa coefficients of $0.90,0.91$, and 0.90 for delayed termination, premature termination, and no cycling asynchrony, respectively. The authors concluded that the algorithm provided waveform analysis equivalent to a human expert.

Chiew et $\mathrm{al}^{37}$ used an iterative airway pressure reconstruction algorithm to represent asynchronous airway pressure waveforms to better match passive breathing airway waveforms using a single compartment model. The reconstructed pressure enabled estimation of the respiratory mechanics of an airway pressure waveform essentially free from asynchrony. This allowed real-time breath-to-breath monitoring and quantification of the magnitude of the asynchrony. Over 100,000 breaths from ventilated subjects with known asynchronous breathing were analyzed. The algorithm was able to reconstruct different types of asynchronous breathing. The resulting respiratory mechanics estimated by the algorithm were more consistent with smaller interquartile range compared to respiratory mechanics estimated using asynchronous pressure. Comparing reconstructed pressure with asynchronous pressure waveforms quantifies the magnitude of asynchronous breathing, which has a median value for the entire dataset of $3.8 \%$. The authors concluded that this method is capable of identifying asynchronous breaths and improving respiratory mechanics estimation compared to conventional model-based methods. It provides an opportunity to automate real-time quantification of asynchronous breathing frequency and magnitude that was previously limited to invasive methods.

Sousa et $\mathrm{al}^{38}$ described a plan for a study they call EPISYNC that uses the Better Care artificial intelligence system to evaluate patient-ventilator synchrony. ${ }^{39,40}$ The Better Care system detects ineffective inspiratory efforts, double-triggering, short cycling, and prolonged cycling. The authors believe that the EPISYNC study will provide important insights into the association between baseline patient characteristics (including mechanics) and the incidence of patient-ventilator asynchrony analyzed during the entire period of mechanical ventilation. They also plan to provide further insight into the association between asynchrony and clinical outcomes such as ventilator-free days and ICU and hospital length of stay.

Marchuk et $\mathrm{al}^{41}$ developed a model to predict the likelihood of asynchronies occurring. They analyzed 10,409,357 breaths from 51 critically ill subjects on mechanical ventilation using the Better Care system. Based on discrete timeseries data representing the total count of asynchronies, they defined 4 levels of risk (very low to very high). A Poisson hidden Markov model ${ }^{42}$ was used to predict the probability of each level of risk occurring in the next period. Long periods with very few asynchronies (and very low risk) were more likely than periods with many events (ie, very high risk). Subjects entering states with a high 


\section{Patient-Ventilator Synchrony}

number of asynchronies were very likely to continue in that state. Whereas other studies detected asynchronies once they have happened, ${ }^{17,20,39,43}$ this was the first study to predict asynchrony events before they happened. The authors speculated that this novel approach is a first step in developing smart alarms so clinicians can consider actions to improve synchrony.

Rehm et $\mathrm{al}^{44}$ developed a machine-learning-based classifier to detect abnormal waveform events. They focused on detecting injurious subtypes of patient-ventilator asynchrony. Using a dataset of breaths recorded from 35 patients, they created computational models to automatically detect and classify 2 types of injurious asynchrony, double-triggering and breath-stacking. The resulting classifier was able to accurately detect double-triggering at a sensitivity of 0.96 and specificity of 0.98 . Breath-stacking was identified with sensitivity of 0.94 and specificity of 0.99 . Nonasynchronous events were identified with a sensitivity of 0.97 and specificity of 0.98 . The authors concluded that it is possible to create a high-performing machinelearning-based model for detecting patient-ventilator asynchrony from mechanical ventilator waveforms in spite of both intrapatient and interpatient variability in waveforms patterns and the presence of artifacts like coughing and suction procedures.

\section{Modes for Improving Synchrony}

To understand how mode selection affects patient-ventilator synchrony, we must first review some basic concepts of mode taxonomy. ${ }^{26}$ Given that the purpose of mechanical ventilation is to support some fraction of the work of breathing, we first recall that work, in terms of the physics of mechanical ventilation, is a function of pressure and volume. It follows that the 2 broad categories of ventilatory modes are volume control and pressure control. These are defined in terms of the equation of motion. Volume control means the operator sets both tidal volume and inspiratory flow; pressure, the dependent variable, will change in relation with patient effort, elastance, and resistance. In contrast, pressure control means that the operator sets the parameters of the airway pressure waveform or the ventilator automatically makes inspiratory pressure proportional to inspiratory effort, thus making volume and flow dependent variables.

Breaths delivered by the ventilator can be either spontaneous (triggered and cycled by the patient) or mandatory (triggered or cycled by the machine). With spontaneous breaths, the timing of the breath is under substantial control of the patient's brain, hence synchrony is maximized. With mandatory breaths, some (or all) of the timing is under the control of the ventilator, which is seldom in synchrony with the patient's demand (although even a broken clock is right twice a day). It follows that modes are comprised of 3 different breath sequences: continuous mandatory ventilation (ie, all breaths are mandatory), intermittent mandatory ventilation (ie, spontaneous breaths may occur between mandatory breaths), and continuous spontaneous ventilation (ie, all breaths are spontaneous). Obviously, modes classified as continuous spontaneous ventilation should provide the highest level of synchrony. This is the reason that the mode called pressure support is so popular for spontaneous breathing trials. Pressure support uses a setpoint targeting scheme, meaning that the inspiratory pressure target is preset by the operator. That target may be too high or too low, however, which can lead to synchrony problems. In contrast, the modes called proportional assist ventilation and NAVA use servo targeting, meaning that the ventilator automatically adjusts inspiratory pressure dynamically in proportion to the patient's inspiratory effort (ie, it amplifies the muscle pressure). Other modes, incorporating a variety of technical features to serve the goals of safety, comfort, and liberation, span a range of potential synchrony issues. Of the currently available modes, volume control continuous mandatory ventilation (also known as volume assist/control) has the least amount of features that serve the goal of comfort. ${ }^{27}$

That said, it should not be surprising that almost all of the articles reviewed studied NAVA. Pettenuzzo et $\mathrm{al}^{45}$ performed a systematic review and meta-analysis of the effect of NAVA on patient-ventilator interaction in mechanically ventilated adults. In several different clinical scenarios, NAVA was associated with significantly reduced asynchrony index (mean difference -8 but very low quality of evidence) and reduced severe asynchrony (odds ratio 0.4 , moderate quality of evidence) compared to pressure support. Other measures of asynchrony were consistently improved, including the NeuroSync Index (defined by Sinderby et $\mathrm{al}^{19}$ ), trigger and cycle delay, and ineffective triggering. There was no difference in auto-triggering, but double-triggering was higher with NAVA. Furthermore, the consequences of double-triggering are very different between NAVA, pressure support, and volume control modes. In volume control, over-assist is most severe because a second tidal volume is forced on top of the one just delivered. In pressure support, inspiratory pressure immediately rises to the preset level and assists the continuing inspiratory effort, but with the result of less over-assist. In NAVA, the breath starts out at baseline pressure and gradually rises in proportion to the effort, so over-assist appears to be less pronounced; however, the effects of NAVA on clinical outcomes remain uncertain. One limitation of this article is that they did not define asynchrony index and, as we have seen, there is little consistency among studies about how it is calculated.

Chen et $\mathrm{al}^{46}$ performed a meta-analysis of clinical trials comparing NAVA with pressure support in adults including clinical outcomes. Asynchrony index was lower in NAVA 


\section{Patient-Ventilator Synchrony}

(ie, -13). In contrast to the other meta-analyses, these authors defined asynchrony index, stating that it is calculated as the number of asynchrony events divided by the sum of respiratory cycles including wasted efforts (ie, ineffective trigger efforts). Auto-triggering and premature triggering were significantly lower with NAVA than with pressure support. There was no difference in double-triggering, ineffective trigger efforts, mean airway pressure, peak airway pressure, tidal volume, minute ventilation, and ventilatory muscle unloading. For clinical outcomes, NAVA resulted in lower duration of ventilation, but there was no difference in ICU mortality, ICU length of stay, and length of hospital stay.

Karikari et $\mathrm{al}^{47}$ performed a meta-analysis of published pediatric studies to compare ventilatory end points between NAVA and conventional ventilation. Asynchrony was $17 \%$ lower, peak inspiratory pressure was $2 \mathrm{~cm} \mathrm{H}_{2} \mathrm{O}$ lower, and $\mathrm{S}_{\mathrm{pO}_{2}}$ was $1 \%$ greater with NAVA. There were no statistically significant differences in PEEP, mean airway pressure, breathing frequency, $\mathrm{pH}, \mathrm{P}_{\mathrm{aO}}$, or $\mathrm{P}_{\mathrm{aCO}}$. Again, a weakness of the analysis is that there is little consistency among studies on how asynchrony is defined. The authors concluded that there is likely minimal clinical importance of these findings because of the small absolute differences. As with the other meta-analyses, the lack of consistency in the definition of asynchrony index makes comparison of these results uncertain (eg, the data given are $-8,-13$, and -17 , whereas we would have expected percentages).

The study by de Waal et $\mathrm{al}^{48}$ described the incidence of patient-ventilator asynchrony in preterm infants treated with nonsynchronized intermittent positive-pressure ventilation delivered through nasal prongs attached to a ventilator. They studied 21 preterm infants (mean gestational age 26 weeks and mean birthweight $905 \mathrm{~g}$ ). Ventilator pressure and flow along with transcutaneous electromyography of the diaphragm were recorded for $1 \mathrm{~h}$. Asynchronies were calculated and classified into 4 types: early inflation (ie, the timing of the mechanical inflation is $>33 \%$ before the spontaneous inflation), late mechanical inflation (ie, the timing of the mechanical inflation is $>33 \%$ after the spontaneous inspiration), early termination of the mechanical inflation (ie, the timing of the mechanical inflation's termination is $>33 \%$ before the spontaneous expiration), and late termination of the mechanical inflation (ie, the timing of the mechanical inflation's termination is $>33 \%$ after the spontaneous expiration). ${ }^{49}$ Furthermore, they calculated an inspiratory asynchrony index calculated as $(100 \times$ asynchronous inspirations/total inspirations) and an expiratory asynchrony index $(100 \times$ asynchronous expirations/total expirations). The mean inspiratory asynchrony index was $68 \%$, and the mean expiratory asynchrony index was $67 \%$. In addition to asynchronous breaths, unsupported breaths and extra mechanical breaths were quite common. The authors concluded that nonsynchronized nasal intermittent positive-pressure ventilation results in high patient-ventilator asynchrony in this population. Further research is needed to determine adverse effects and to develop new methods of synchronizing nasal intermittent positive-pressure ventilation.

Longhini et $\mathrm{al}^{50}$ conducted 30 -min trials of NAVA using a helmet or pressure support with a face mask in 10 subjects with COPD exacerbation. They assessed subject comfort, breathing frequency, respiratory drive, arterial blood gases, pressure-time product, inspiratory trigger delay, and asynchrony index. Asynchronies detected were ineffective efforts, auto-triggering, and double-triggering. The index was calculated as the total number of asynchronies divided by the number of breaths, and an asynchrony index $\geq 10 \%$ was considered clinically important. ${ }^{49}$ They reported that NAVA improved comfort and that respiratory drive was slightly decreased. Gas exchange and pressure-time product did not differ, but trigger performance, patient-ventilator interaction, and synchrony were improved with NAVA.

Lamouret et $\mathrm{al}^{51}$ compared ventilator synchrony between pressure support and NAVA in tracheostomized subjects. They categorized asynchronies into 2 groups; macro-asynchronies (ie, ineffective triggering, double-triggering, and auto-triggering) and micro-asynchronies (ie, inspiratory trigger delay, premature cycling, and late cycling). This was a prospective, sequential, nonrandomized, single-center study in an ICU in France. Analysis of ventilator waveforms was performed by 2 independent physicians using data recorded for 16 min per subject. Breathing frequency was determined from the $\mathrm{EA}_{\mathrm{di}}$ signal, and an asynchrony index was calculated as $(100 \times$ total number of asynchronies/breathing frequency). An asynchrony index was also calculated for each subtype of asynchrony. The total asynchrony index was lower for NAVA than for pressure support ( $2 \%$ vs $14 \%$ ), and an asynchrony index $>10 \%$ was less frequent for NAVA. Among the macro-asynchronies there was no difference in auto-triggering and ineffective triggering between the 2 groups, although there was more double-triggering in NAVA. For micro-asynchronies, there were fewer of each type in NAVA. The tidal volume was lower with NAVA than with pressure support (5.8 vs 6.2 $\mathrm{mL} / \mathrm{kg}$ ). The breathing frequency was higher with NAVA (28 vs 26 breaths/min). The authors claimed that this was the first study to compare NAVA and pressure support and suggest that more research is needed to determine the effects of NAVA on clinical outcomes in this population.

Grieco et $\mathrm{al}^{52}$ compared conventional pressure support with SmartCare/PS, a mode classified as pressure control continuous spontaneous ventilation with intelligent targeting, meaning use of artificial intelligence. ${ }^{26}$ This targeting scheme automatically adjusts the inspiratory pressure target to keep the patient within a comfort zone defined as a 


\section{Patient-Ventilator Synchrony}

breathing frequency of $15-30$ breaths/min $(<34$ for neurological patients), tidal volume above a minimum threshold established from the patient's height, and end-tidal $\mathrm{CO}_{2}<$ $55 \mathrm{~mm} \mathrm{Hg}$ (65 mm Hg for patients with COPD). These authors defined the criteria for identifying the following asynchronies: auto-triggering (ie, ventilator cycle without prior decrease in airway pressure), wasted efforts (ie, depression in the airway pressure signal $\geq 0.5 \mathrm{~cm} \mathrm{H}_{2} \mathrm{O}$ associated with an abrupt rise in expiratory flow but not followed by flow delivery from the ventilator), double-cycling (ie, 2 ventilator cycles separated by less than one half the mean inspiratory time, with the first cycle being subject-triggered), and short cycling (ie, inspiratory time shorter than one half the mean inspiratory time). They provided pressure and flow waveforms to illustrate these asynchronies. They calculated an asynchrony index as the number of asynchronies divided by the sum of ventilator breaths, wasted efforts, and double cyclings. The asynchrony index was lower with SmartCare than with pressure support (5 vs 7), but there was no difference in the proportion of subjects with asynchronies. The inspiratory pressure target varied more with SmartCare, but the average level was not different between the 2 modes. In subjects with baseline inspiratory pressure target $<12 \mathrm{~cm} \mathrm{H}_{2} \mathrm{O}$, tidal volume was lower with SmartCare. The authors concluded that during difficult weaning, SmartCare improved patient-ventilator interactions by lowering tidal volume and enhancing inspiratory pressure target variability.

One might expect there to be more studies on the effect of proportional assist on synchrony, but we found only 2 in the last 2 years. Zang et $\mathrm{al}^{53}$ published a paper in RESPIRATORY CARE comparing patient-ventilator interaction during different levels of noninvasive proportional assist ventilation with noninvasive pressure support. This was a study of 15 subjects with severe COPD and hypercapnia. The proportional assist and pressure support levels were set by subject comfort. To evaluate patient-ventilator interaction, the neural respiratory drive, respiratory muscle effort, flow, and airway pressure signals were measured. Results indicated that the expiratory cycle delay, calculated as the time between the end of diaphragm electromyogram $\left(\mathrm{EMG}_{\mathrm{di}}\right)$ signal and the end of the inspiratory flow, progressively increased with increasing assist level in both modes. However, the delay was longer in each assist level during proportional assist. The runaway phenomenon was observed with proportional assist ventilation, with runaway defined as the ventilator being unable to accurately assess lung mechanics and continuing to increase the inspiratory pressure until the high pressure alarm is activated. Consistent runaway means the mode has failed. The time between the peak of the $\mathrm{EMG}_{\mathrm{di}}$ signal and the maximum value of the flow signal and the time difference between the peak $\mathrm{EMG}_{\mathrm{di}}$ and peak inspiratory pressure were significantly increased with increasing assist level in proportional assist ventilation.
Amargiannitakis et $\mathrm{al}^{54}$ conducted a study in an attempt to validate an algorithm for titrating assistance in proportional assist ventilation previously described by Carteaux et al. ${ }^{55}$ Data from 26 subjects ventilated with proportional assist ventilation were used to compare the estimated peak $\mathrm{P}_{\text {mus }}$ (from the algorithm) with measurements of transdiaphragmatic pressure and derived pressure-time product. The sensitivity and specificity of estimated peak $P_{\text {mus }}$ to predict the range of actual inspiratory effort were $81 \%$ and $58 \%$, respectively. In $49 \%$ of cases, the level of assist indicated by the algorithm differed from that indicated by the transdiaphragmatic pressure and pressure-time product. The authors concluded that the algorithm had limited accuracy in indicating the appropriate level of support.

\section{Effects of Sedation}

de Haro et $\mathrm{al}^{56}$ conducted a prospective, multicenter observational study on the effects of sedatives and opioids on trigger and cycling asynchronies in critically ill subjects. They used the Better Care system to continuously monitor ineffective trigger efforts, double-cycling, and asynchrony index as well as modes of ventilation. The Better Care system identifies modes using concepts from our ventilator mode taxomony. ${ }^{26,40}$ In 79 subjects, $14,166,469$ breaths were recorded during $579 \mathrm{~d}$ of ventilation. Overall asynchronies were not different in days classified as sedativeonly and sedatives plus opioids and were more prevalent in days classified as no-drugs than in those classified as sedatives plus opioids, irrespective of the mode of ventilation. However, on days classified as sedative plus opioids, higher sedative doses and deeper sedation resulted in more ineffective trigger efforts and higher asynchrony index. Opioid dosing was inversely associated with overall asynchronies. The authors concluded that sedatives alone or with opioids do not decrease asynchronies beyond what can't be achieved with opioids alone, independently of the mode of ventilation. Hence, optimal titration of opioids might improve patient-ventilator interaction while avoiding the deleterious effects of sedatives.

\section{Toward a Taxonomy for Patient- Ventilator Synchrony}

Any sufficiently advanced science eventually become useless without a taxonomy (ie, a classification system) based on a standardized vocabulary. Without this, we are in the unfortunate position of requiring the learner to "understand what I mean, not what I say." We found only one article that addressed this topic.

Gonzalez-Bermejo et al ${ }^{57}$ created a conceptual framework for systematic analysis of polygraphic recordings of subjects undergoing noninvasive ventilation. Definition, description, pathophysiologic mechanisms, and classification 


\section{Patient-Ventilator Synchrony}

of patient-ventilator asynchrony were the result of consensus of clinicians after visual inspection of polygraph tracings. These were then reproduced using a breathing simulator. The authors defined 9 different asynchronies, in 2 broad categories, all confirmed by reproduction on the simulator. The first category was rate asynchronies, defined as a mismatch between ventilator and patient rates. When the ventilator rate was above the subject rate, the following events were identified: double-triggering, auto-triggering, and uncoupling. Uncoupling had 2 varieties, isolated uncoupling and reversetriggering (this one they were unable to reproduce on the simulator). When the subject rate was above the ventilator rate, they identified ineffective efforts. When subject and ventilator rates were completely dissociated, they described it as prolonged uncoupling. The second major category was intracycle asynchronies, defined as distortions of the flow and pressure waveforms during both inspiration and expiration. When a distortion of the inspiratory waveforms occurred during inspiration or lasted for the entire cycle, they defined it as intracycle under-assistance. When the end of the pressure and flow waveforms were out of phase with the signals from the thoracic or abdominal belts, they defined it as delayed cycling or premature cycling. They noted that no asynchrony is specific or pathognomonic of a given pathophysiological situation.

We conclude that the subject of patient-ventilator interaction taxonomy has not been adequately addressed in the literature to date. Taxonomies have 2 components: a set of definitions relevant to the topic (ie, a standardized vocabulary) and a hierarchical organizational structure using key definitions (ie, the taxonomy). ${ }^{58}$ Regarding a standardized vocabulary, we can see some minor inconsistencies in the literature. For example, authors use ineffective triggering synonymously with ineffective trigger efforts. If we accept the definition of triggering as the start of the inspiratory time, signaled by the start of flow from the ventilator, then ineffective triggering is illogical: something that did not occur can neither be effective nor ineffective. Also, if we accept cycling to mean the end of the inspiratory time signaled by the start of expiratory flow, then using doublecycling as synonymous with auto-triggering is simply inconsistent. Of more concern is the common usage of the term asynchrony. To understand this we must first review some basics of signal analysis and develop a distinction between asynchrony and asynchrony.

As stated above, patient-ventilator interactions are described with multiple names. The following definitions are based on published literature and general physics definitions. In the interaction of 2 systems, the patient and the ventilator, there must be one that serves as a reference for the other. The reference waveform is the one that represents the "true" signal, which any other waveform should match for synchrony to occur. The reference waveform, in the patient-ventilator relationship, is the signal generated by the patient's breathing efforts. Ideally, we would acquire this signal directly from the brain..$^{59}$ In practice, however, we currently start with the phrenic nerve activation of the diaphragm $\left(\mathrm{EA}_{\mathrm{di}}\right)$. Upon muscle activation, changes in transpulmonary pressure are detected as changes in pressure and flow. With the introduction of NAVA, $\mathrm{EA}_{\mathrm{di}}$ allows for a fairly accurate reference signal for assessing patientventilator synchrony as a surrogate for $\mathrm{P}_{\text {mus }}$. A practical alternative would be an esophageal pressure signal. A method of calculating $\mathrm{P}_{\text {mus }}$ itself as a reference signal has been described but never commercialized. ${ }^{14,16}$ It follows that, in making a definition, we must use the true reference standard. In practice, we often do not have a direct measurement of the reference standard. Thus we make inferences on the patient breathing efforts from the changes in the pressure waveform (if in volume control mode) or the flow waveform (if in pressure control mode).

We can define patient-ventilator synchrony as a nearzero phase difference between the patient signal (eg, esophageal pressure or $\mathrm{EA}_{\mathrm{di}}$ ) and ventilator response. A phase difference will always exist if for no other reason that the ventilator cannot respond instantaneously (ie, in zero time). Hence, we must use the terms near-zero phase difference or clinically unimportant phase difference to describe synchrony. An adequate description of phase and phase difference is beyond the scope of this article, but many good resources are available on the Internet. One thing to remember is that when we describe the respiratory system as a single compartment model (eg, using the equation of motion), pressure, volume, and flow signals are always out of phase in proportion to the system impedance, dependent on resistance and compliance. Hence, it is important to compare similar signals when describing synchrony (eg, pressure vs pressure, flow vs flow). This is a concept from basic circuit analysis.

Dyssynchrony (from $d y s^{-}$, meaing difficult, abnormal, bad) is a clinically important phase difference between patient demand and ventilator response. In this circumstance, both waveforms exist, yet their timing is significantly out of phase. In contrast, asynchrony (from $a$-, meaing absence of) is the absence of either a patient signal (ie, demand or inspiratory effort) or a ventilator response. In these circumstances, there can be no synchrony because either the reference signal or the ventilator signal is not present.

Notice that synchrony issues, by definition, have to do with timing. As such there are 2 defined timing points in a breath, for the patient the beginning and end of the effort, and for the ventilator the trigger and cycle of inspiration. If we focus on these discrete events, there are only 5 possibilities in terms of timing, which apply to both triggering and cycling: (1) normal, (2) early in reference to the patient, (3) late in reference to the patient, (4) missed the patient signal, and (5) false signal (a non- $\mathrm{P}_{\text {mus }}$ signal). 


\section{PATIENT-VENTILATOR SyNChrony}
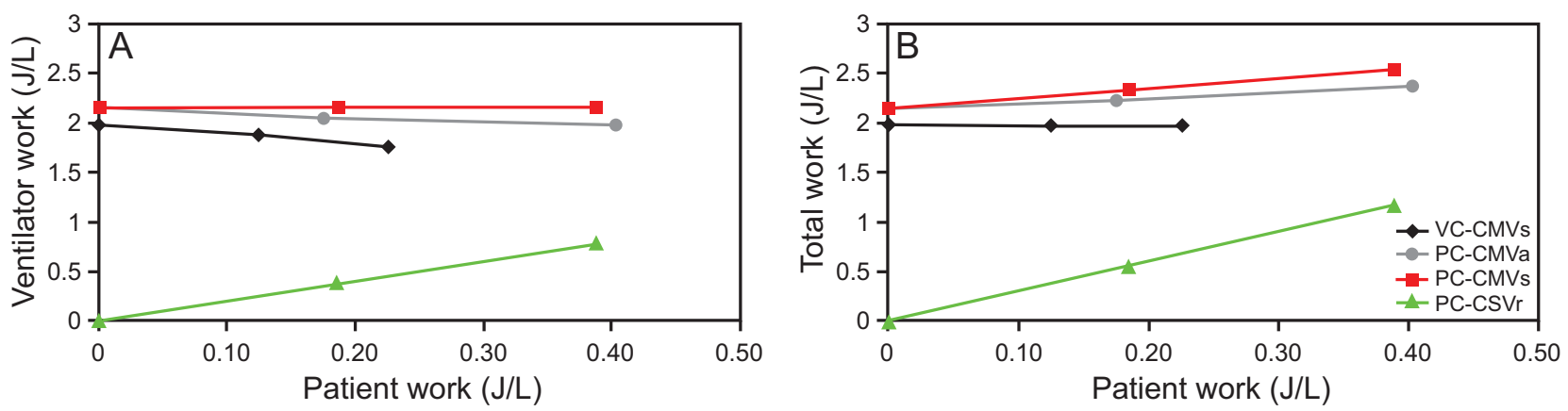

Fig. 1. Comparison of work shifting between volume control continuous mandatory ventilation with set-point targeting (VC-CMVs, eg volume assist/control), pressure control continuous mandatory ventilation with adaptive targeting (PC-CMVa, eg, Presssure Regulated Volume Control), pressure control continuous mandatory ventilation with set-point targeting (PC-CMVs, eg, pressure assist/control), and pressure control continuous spontaneous ventilation with servo targeting (PC-CSVr, eg, proportional assist ventilation). Maximum inspiratory effort $\left(P_{\text {mus }}\right)$ set at 0,3 , and $6 \mathrm{~cm} \mathrm{H}_{2} \mathrm{O}$. For VC-CMVs and PC-CMVa, the tidal volume target is $0.400 \mathrm{~L}$. For PC-CSVr, the tidal volume target was set at $0.200 \mathrm{~L}$ and at $0.400 \mathrm{~L}$, and the ventilator work was set at $75 \%$ of total work.

During inspiration (ie, the period between trigger and cycle) and expiration (ie, the period between cycle and next trigger), the main issues are not related to timing but to work of breathing. Indeed, we look at these periods to identify patient-ventilator interactions, but these periods also contain a fair amount of information in terms of work of breathing. The equation of motion can be modified to calculate the work of inspiration (in joules, J) or work per unit of tidal volume $(\mathrm{J} / \mathrm{L})$ by integration of the pressure terms with respect to volume. ${ }^{60}$ For passive ventilation $\left(\mathrm{P}_{\text {mus }}=0\right)$, the ventilator does all the work. For example, in the simplest case where $\mathrm{P}_{\text {vent }}$ is held constant, work is just $\mathrm{P}_{\text {vent }} \times$ tidal volume. On the other hand, when ventilatory assistance is zero (eg, CPAP), then all the work is done by the patient (ie, $\mathrm{P}_{\text {mus }}$ generates the tidal volume).

Recall that work is defined as force acting through a distance or, in physiology, as pressure used to deliver a volume to the respiratory system. If we define a ventilator as an automated system that supplies some portion of the work of breathing, then it makes sense that the 2 main control variables for the taxonomy of modes are volume and pressure. When $\mathrm{P}_{\text {vent }}$ and $\mathrm{P}_{\text {mus }}$ are active together, some portion of the total work is done by the ventilator and some by the patient. We call this situation work shifting. We can create a simple work shifting index (WSI) to indicate the amount of total work $\left(\mathrm{W}_{\mathrm{tot}}\right)$ shifted from the ventilator to the patient $\left(\mathrm{W}_{\mathrm{pt}}\right)$ : WSI $=\left(\mathrm{W}_{\mathrm{pt}} / \mathrm{W}_{\text {tot }}\right) \times 100$.

Hence, if the ventilator does all the work, the WSI = $0 \%$; if the patient does all the work, the WSI $=100 \%$, and if the work is shared equally between the ventilator and patient, the WSI $=50 \%$. Work shifting occurs in 4 main patterns (Fig. 1). First, for volume controlled inspiration with set-point targeting, the total work stays constant because volume and flow are unaffected by $\mathrm{P}_{\text {mus }}$. Hence, $\mathrm{P}_{\text {vent }}$ (and ventilator work) must decrease in exact proportion to the increase in $\mathrm{P}_{\mathrm{mus}}$ (and patient work) for each breath. The WSI for the example shown in Figure 1 goes from $0 \%$ to $6 \%$ to $12 \%$ as maximum $\mathrm{P}_{\text {mus }}$ increases from 0 to 3 to $6 \mathrm{~cm} \mathrm{H}_{2} \mathrm{O}$, respectively. It would be recognized graphically as an increasing distortion of the pressure-time waveform (Fig. 2). The extreme of work shifting is when the patient generates high levels of $\mathrm{P}_{\text {mus }}$, and $\mathrm{P}_{\text {vent }}$ decreases below baseline (PEEP). In this case, the patient is actually doing work on the ventilator system. This extreme is called flow starvation and is most commonly seen during volume control ventilation with set-point targeting.

Second, during pressure controlled ventilation with adaptive targeting (eg, Pressure Regulated Volume Control), the average tidal volume (over several breaths) is the result of the combined average work of $\mathrm{P}_{\text {mus }}$ and $\mathrm{P}_{\mathrm{vent}}$ to deliver volume. Hence, as $\mathrm{P}_{\text {mus }}$ increases, $\mathrm{P}_{\text {vent }}$ must decrease (similar to volume controlled ventilation) to keep the average tidal volume at the preset target value. This effect is similar to that during volume controlled ventilation, but in the simulation shown in Figure 1 it is an even more extreme case of work shifting. The difference is that the total work increases because the tidal volume increases. The WSI for the example shown in Figure 1 goes from $0 \%$ to $8 \%$ to $17 \%$ as maximum $\mathrm{P}_{\mathrm{mus}}$ increases from 0 to 3 to $6 \mathrm{~cm} \mathrm{H}_{2} \mathrm{O}$, respectively.

Third, for pressure controlled inspiration with set-point targeting, $\mathrm{P}_{\text {vent }}$ remains unaffected by $\mathrm{P}_{\text {mus }}$ while volume and flow increase as $P_{\text {mus }}$ increases (Fig. 3). Because pressure, volume, and flow all increase, the total work increases while the relation between ventilator work and patient work (expressed as work per liter) stays relatively constant. Again, work shifts as the patient accounts for more of the total work. The WSI for the example shown in Figure 1 goes from $0 \%$ to $8 \%$ to $15 \%$ as maximum $\mathrm{P}_{\text {mus }}$ increases from 0 to 3 to $6 \mathrm{~cm} \mathrm{H}_{2} \mathrm{O}$, respectively. 


\section{Patient-Ventilator Synchrony}
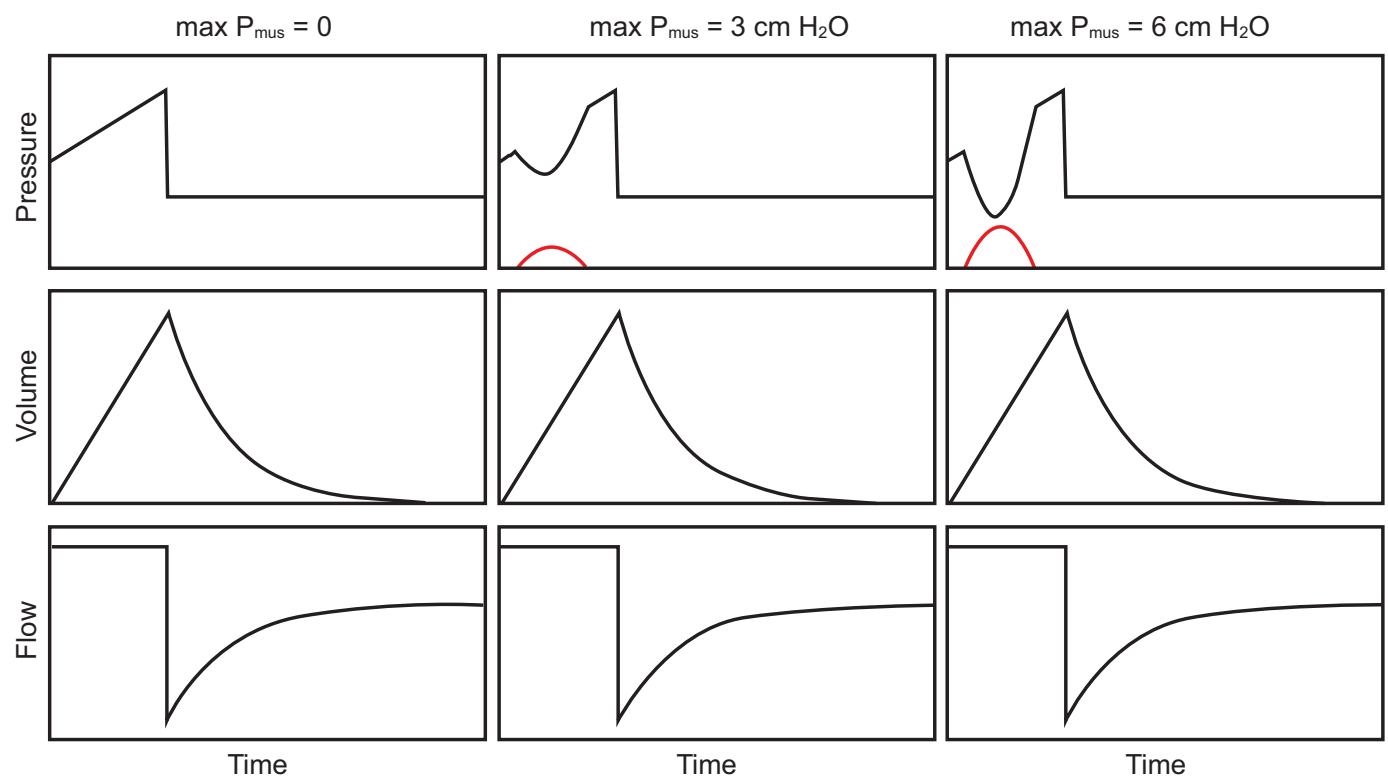

Fig. 2. Work shifting due to active inspiratory effort in volume controlled ventilation. Red lines are muscle pressure $\left(P_{\text {mus }}\right)$, representing inspiratory effort.
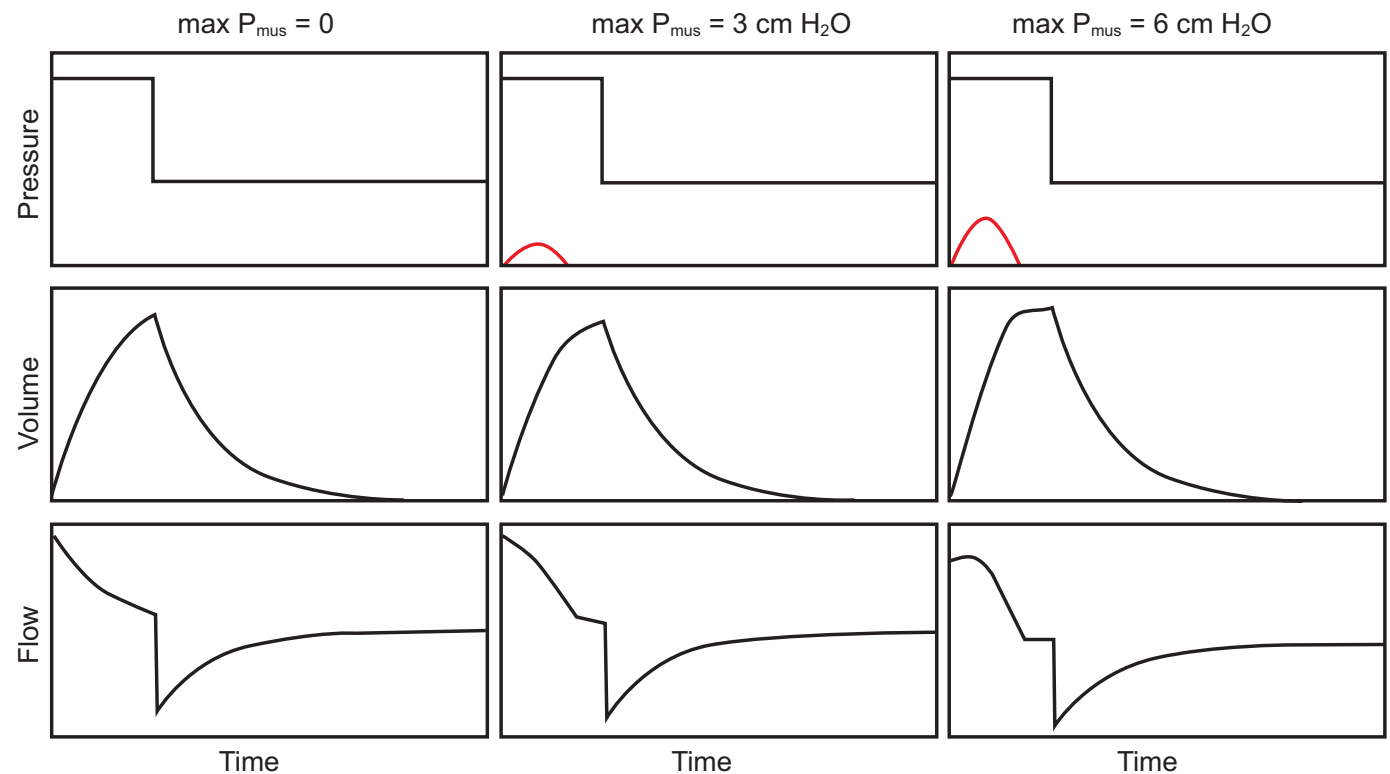

Fig. 3. Work shifting due to active inspiratory effort in pressure controlled ventilation. Red lines are muscle pressure $\left(P_{\text {mus }}\right)$, representing inspiratory effort.

The forth pattern is no work shifting. Proportional assist ventilation was invented to keep the relation between ventilator and patient work constant and controllable. ${ }^{61}$ These situations are illustrated in Figure 1.

If we can agree on a standardized vocabulary for patient-ventilator interactions, then we need to develop a standardized approach for analyzing the waveforms. In practice, we have relied on bedside recognition of patterns in the waveforms by human experts to diagnose synchrony problems, but no method has yet been accepted as a standard. Indeed, ventilators have only recently been able to provide precise waveform display and analysis tools, and clinicians generally have not been trained to use them for diagnostic purposes. Contrast this with the success story of electrocardiograms (ECGs). Caregivers are expected to be able to read or at least draw a normal ECG waveform. We are trained to read waveform landmarks, in a particular order, starting with the P, Q, R, S, 


\section{Patient-Ventilator Synchrony}

Table 2. A Method to Read Ventilator Waveforms

\begin{tabular}{ll}
\hline \hline Patient-Ventilator Interaction & \multicolumn{1}{c}{ What To Look For } \\
\hline $\begin{array}{l}\text { Phase 1: Trigger } \\
\text { Normal }\end{array}$ & Triggering within $300 \mathrm{~ms}$ of patient trigger signal \\
Early & Machine triggering followed by patient trigger signal within the same inspiration \\
Late & Trigger delay $>300 \mathrm{~ms}$ after patient trigger signal \\
False & Measured breathing frequency higher than set rate with no evidence of patient triggering \\
Missed & Patient effort fails to trigger ventilator, expiratory flow waveform deflected toward baseline \\
Phase 2: Inspiration & \\
Normal & Passive (no inspiratory effort) or clinically unimportant work shifting \\
Work shifting & Compared to passive inflation, decreased mean inspiratory pressure in volume control or increased flow and \\
& volume in pressure control; due to inspiratory effort \\
Phase 3: Cycle & No evidence of early or late cycling \\
Normal & Distortion of early peak expiratory flow (toward baseline) \\
Early & Rise in pressure at end inspiration \\
Late & Spike in inspiratory pressure activates high pressure alarm and ending breath \\
False & Ventilator fails to recognize patient cycling signal (eg, in proportional assist ventilation, runaway) \\
Missed &
\end{tabular}

$\mathrm{T}$, and then to reach a diagnosis. The ventilator waveforms carry as much information as ECG waveforms, if not more. It follows, then, that to describe the patient-ventilator interactions, we must interpret waveforms in a systematic fashion. In clinical practice, we do not always have esophageal pressure or $\mathrm{EA}_{\mathrm{di}}$ signals available for reference. Therefore, we must rely on the ventilator airway waveforms (pressure, flow, and volume) to infer the effects of $P_{\text {mus. }}$.

Table 1 outlines the types of patient-ventilator interactions, alternative names, and definitions, and Table 2 outlines the potential types of interactions according to phase of the breath. The reader will note that one can progress through each one of the breath phases and describe different patient-ventilator interactions in a single breath. We suggest consideration of 2 ideas. The first is that we need to move away from just thinking about pattern recognition. For example, multiple-triggering, also known as double-triggering, is a pattern that has multiple causes (eg, false triggering, early triggering, early cycle), yet it does not help identify the type of discordance. Consider the problem of defining reverse-triggering. If we use the proposed method, and we use the definition of reverse-triggering as a form of early trigger (ie, $\mathrm{P}_{\mathrm{vent}}$ starts before $\mathrm{P}_{\mathrm{mus}}$ ), the practitioner can now understand that it often leads to early cycling because $P_{\text {mus }}$ is just getting under way when $P_{\text {vent }}$ ceases. Early cycling, due to the early trigger, is a common cause of double-triggering, making early cycling a necessary but not sufficient cause of double-triggering. Thus the student learns that the pattern of double-trigger has several causes. The second idea is that having a specific interpretation method helps organize the way we read the waveforms so that important things are not missed. Eventually pattern recognition emerges as a key skill, but the method takes us beyond simple memorization into a deeper understanding of the physics of patient-ventilator interaction.

\section{Summary}

Patient-ventilator synchrony is a popular topic and much research has been conducted recently in terms of both detecting and correcting synchrony problems. Nevertheless, there is a lack of convincing evidence that synchrony problems affect patient outcomes in specific ways. Development of automated detection systems may help generate the needed data, but for such data to be of much use, we must come to consensus on a standardized vocabulary and taxonomy for patient-ventilator interactions.

\section{REFERENCES}

1. Garofalo E, Bruni A, Pelaia C, Liparota L, Lombardo N, Longhini F, et al. Recognizing, quantifying and managing patient-ventilator asynchrony in invasive and noninvasive ventilation. Expert Rev Respir Med 2018;12(7):557-567.

2. Bruni A, Garofalo E, Pelaia C, Messina A, Cammarota G, Murabito P, et al. Patient-ventilator asynchrony in adult critically ill patients. Minerva Anestesiol 2019;85(6):676-688.

3. Mireles-Cabodevila E, Chatburn RL. The challenge of patient-ventilator interactions and technological solutions. AARC Times 2017;41 (6):9-14.

4. Fabry B, Guttmann J, Eberhard L, Bauer T, Haberthür C, Wolff G. An analysis of desynchronization between the spontaneously breathing 


\section{Patient-Ventilator SynChrony}

patient and ventilator during inspiratory pressure support. Chest 1995; 107(5):1387-1394.

5. Marini JJ, Capps JS, Culver BH. The inspiratory work of breathing during assisted mechanical ventilation. Chest 1985;87(5):612-618.

6. MacIntyre NR, McConnell R, Cheng KC, Sane A. Patient-ventilator flow dyssynchrony: flow-limited versus pressure-limited breaths. Crit Care Med 1997;25(10):1671-1677.

7. Flick GR, Bellamy PE, Simmons DH. Diaphragmatic contraction during assisted mechanical ventilation. Chest 1989;96(1):130-135.

8. Kallet RH, Campbell AR, Dicker RA, Katz JA, Mackersie RC. Work of breathing during lung-protective ventilation in patients with acute lung injury and acute respiratory distress syndrome: a comparison between volume and pressure-regulated breathing modes. Respir Care 2005;50(12):1623-1631.

9. Akoumianaki E, Lyazidi A, Rey N, Matamis D, Perez-Martinez N, Giraud R, et al. Mechanical ventilation-induced reverse-triggered breaths: a frequently unrecognized form of neuromechanical coupling. Chest 2013;143(4):927-938

10. Chao DC, Scheinhorn DJ, Stearn-Hassenpflug M. Patient-ventilator trigger asynchrony in prolonged mechanical ventilation. Chest 1997; 112(6):1592-1599.

11. Kondili E, Prinianakis G, Georgopoulos D. Patient-ventilator interaction. Br J Anaesth 2003;91(1):106-119.

12. Georgopoulos D, Prinianakis G, Kondili E. Bedside waveforms interpretation as a tool to identify patient-ventilator asynchronies. Intensive Care Med 2006;32(1):34-47.

13. Thille AW, Rodriguez P, Cabello B, Lellouche F, Brochard L. Patientventilator asynchrony during assisted mechanical ventilation. Intensive Care Med 2006;32(10):1515-1522.

14. Younes M, Brochard L, Grasso S, Kun J, Mancebo J, Ranieri M, et al. A method for monitoring and improving patient: ventilator interaction. Intensive Care Med 2007;33(8):1337-1346.

15. Younes M. Proportional assist ventilation, a new approach to ventilatory support: theory. Am Rev Respir Dis 1992;145(1):114-120.

16. Kondili E, Alexopoulou C, Xirouchaki N, Vaporidi K, Georgopoulos D. Estimation of inspiratory muscle pressure in critically ill patients. Intensive Care Med 2010;36(4):648-655.

17. Mulqueeny Q, Ceriana P, Carlucci A, Fanfulla F, Delmastro M, Nava $\mathrm{S}$. Automatic detection of ineffective triggering and double triggering during mechanical ventilation. Intensive Care Med 2007;33(11):20142018.

18. Mulqueeny Q, Redmond SJ, Tassaux D, Vignaux L, Jolliet P, Ceriana $\mathrm{P}$, et al. Automated detection of asynchrony in patient-ventilator interaction. Conf Proc IEEE Eng Med Biol Soc 2009;2009:5324-5327.

19. Sinderby C, Liu S, Colombo D, Camarotta G, Slutsky AS, Navalesi P, et al. An automated and standardized neural index to quantify patientventilator interaction. Crit Care 2013;17(5):R239.

20. Gutierrez G, Ballarino GJ, Turkan H, Abril J, De La Cruz L, Edsall C, et al. Automatic detection of patient-ventilator asynchrony by spectral analysis of airway flow. Crit Care 2011;15(4):R167.

21. de Wit M, Pedram S, Best AM, Epstein SK. Observational study of patient-ventilator asynchrony and relationship to sedation level. J Crit Care 2009;24(1):74-80.

22. de Haro C, Ochagavia A, Lopez-Aguilar J, Fernandez-Gonzalo S, Navarra-Ventura G, Magrans R, et al. Patient-ventilator asynchronies during mechanical ventilation: current knowledge and research priorities. Intensive Care Med Exp 2019;7(Suppl 1):43.

23. Pham T, Telias I, Piraino T, Yoshida T, Brochard LJ. Asynchrony consequences and management. Crit Care Clin 2018;34(3):325-341.

24. Holanda MA, Vasconcelos RDS, Ferreira JC, Pinheiro BV. Patientventilator asynchrony. J Bras Pneumol 2018;44(4):321-333.

25. Arnal JM, Garnero A, Saoli M, Chatburn RL. Parameters for simulation of adult subjects during mechanical ventilation. Respir Care 2018;63(2):158-168
26. Chatburn RL, El-Khatib M, Mireles-Cabodevila E. A taxonomy for mechanical ventilation: 10 fundamental maxims. Respir Care 2014;59 (11): 1747-1763.

27. Mireles-Cabodevila E, Hatipoğlu U, Chatburn RL. A rational framework for selecting modes of ventilation. Respir Care 2013;58(2):348366.

28. Bulleri E, Fusi C, Bambi S, Pisani L. Patient-ventilator asynchronies: types, outcomes and nursing detection skills. Acta Biomed 2018;89 (7-s):6-18.

29. Blokpoel RGT, Wolthuis DW, Koopman AA, Kneyber M. Reverse triggering: a novel type of patient-ventilator asynchrony in mechanically ventilated children. Am J Respir Crit Care Med 2019;200(2): e4-e5.

30. Carnevale FA, Razack S. An item analysis of the COMFORT scale in a pediatric intensive care unit. Pediatr Crit Care Med 2002;3(2):177180.

31. Su HK, Loring SH, Talmor D, Baedorf Kassis E. Reverse triggering with breath stacking during mechanical ventilation results in large tidal volumes and transpulmonary pressure swings. Intensive Care Med 2019;45(8):1161-1162.

32. de Haro C, López-Aguilar J, Magrans R, Montanya J, FernándezGonzalo S, Turon M, et al. Double cycling during mechanical ventilation: frequency, mechanisms, and physiologic implications. Crit Care Med 2018;46(9):1385-1392

33. Soilemezi E, Vasileiou M, Spyridonidou C, Tsagourias M, Matamis D. Understanding patient-ventilator asynchrony using diaphragmatic ultrasonography. Am J Respir Crit Care Med 2019;200(4):e27-e28.

34. Matamis D, Soilemezi E, Tsagourias M, Akoumianaki E, Dimassi S, Boroli F, et al. Sonographic evaluation of the diaphragm in critically ill patients. Technique and clinical applications. Intensive Care Med 2013;39(5):801-810.

35. Sottile PD, Albers D, Higgins C, McKeehan J, Moss MM. The association between ventilator dyssynchrony, delivered tidal volume, and sedation using a novel automated ventilator dyssynchrony detection algorithm. Crit Care Med 2018;46(2):e151-e157.

36. Gholami B, Phan TS, Haddad WM, Cason A, Mullis J, Price L, et al. Replicating human expertise of mechanical ventilation waveform analysis in detecting patient-ventilator cycling asynchrony using machine learning. Comput Biol Med 2018;97:137-144.

37. Chiew YS, Tan CP, Chase JG, Chiew YW, Desaive T, Ralib AM, Mat Nor MB. Assessing mechanical ventilation asynchrony through iterative airway pressure reconstruction. Comput Methods Programs Biomed 2018; 157:217-224.

38. Sousa MLA, Magrans R, Hayashi FK, Blanch L, Kacmarek RM, Ferreira JC. EPISYNC study: predictors of patient-ventilator asynchrony in a prospective cohort of patients under invasive mechanical ventilation - study protocol. BMJ Open 2019;9(5):e028601.

39. Blanch L, Sales B, Montanya J, Lucangelo U, Garcia-Esquirol O, Villagra A, et al. Validation of the Better Care(R) system to detect ineffective efforts during expiration in mechanically ventilated patients: a pilot study. Intensive Care Med 2012;38(5):772-780.

40. Murias G, Montanyà J, Chacón E, Estruga $\mathrm{A}$, Subirà C, Fernández R, et al. Automatic detection of ventilatory modes during invasive mechanical ventilation. Crit Care 2016;20(1):258.

41. Marchuk Y, Magrans R, Sales B, Montanya J, López-Aguilar J, de Haro C, et al. Predicting patient-ventilator asynchronies with hidden Markov models. Sci Rep 2018;8(1):17614.

42. Baum L, Petrie T. Statistical inference for probabilistic functions of finite state Markov chains. Ann Math Statist 1966;37(6):1554-1563.

43. Longhini F, Colombo D, Pisani L, Idone F, Chun P, Doorduin J, et al. Efficacy of ventilator waveform observation for detection of patientventilator asynchrony during NIV: a multicentre study. ERJ Open Res 2017;3(4):00075-2017. 


\section{PATIENT-Ventilator SynChrony}

44. Rehm GB, Han J, Kuhn BT, Delplanque JP, Anderson NR, Adams JY, et al. Creation of a robust and generalizable machine learning classifier for patient ventilator asynchrony. Methods Inf Med 2018;57(4):208219.

45. Pettenuzzo T, Aoyama H, Englesakis M, Tomlinson G, Fan E. Effect of neurally adjusted ventilatory assist on patient-ventilator interaction in mechanically ventilated adults: a systematic review and meta-analysis. Crit Care Med 2019;47(7):e602-e609.

46. Chen C, Wen T, Liao W. Neurally adjusted ventilatory assist versus pressure support ventilation in patient-ventilator interaction and clinical outcomes: a meta-analysis of clinical trials. Ann Transl Med 2019;7(16):382.

47. Karikari S, Rausa J, Flores S, Loomba RS. Neurally adjusted ventilatory assist versus conventional ventilation in the pediatric population: are there benefits? Pediatr Pulmonol 2019;54(9):1374-1381.

48. de Waal CG, van Leuteren RW, de Jongh FH, van Kaam AH, Hutten GJ. Patient-ventilator asynchrony in preterm infants on nasal intermittent positive pressure ventilation. Arch Dis Child Fetal Neonatal Ed 2019;104(3):F280-F284

49. Vignaux L, Vargas F, Roeseler J, Tassaux D, Thille AW, Kossowsky MP, et al. Patient-ventilator asynchrony during non-invasive ventilation for acute respiratory failure: a multicenter study. Intensive Care Med 2009;35(5):840-846.

50. Longhini F, Liu L, Pan C, Xie J, Cammarota G, Bruni A, et al. Neurally-adjusted ventilatory assist for noninvasive ventilation via a helmet in subjects with COPD exacerbation: a physiologic study. Respir Care 2019;64(5):582-589.

51. Lamouret O, Crognier L, Vardon Bounes F, Conil JM, Dilasser C, Raimondi T, et al. Neurally adjusted ventilatory assist (NAVA) versus pressure support ventilation: patient-ventilator interaction during invasive ventilation delivered by tracheostomy. Crit Care 2019;23(1):2.

52. Grieco DL, Bitondo MM, Aguirre-Bermeo H, Italiano S, Idone FA, Moccaldo A, et al. Patient-ventilator interaction with conventional and automated management of pressure support during difficult weaning from mechanical ventilation. J Crit Care 2018;48:203-210.

53. Zhang J, Luo Q, Chen R. Patient-ventilator interaction with noninvasive proportional assist ventilation in subjects with COPD. Respir Care 2020;65(1):45-52.

54. Amargiannitakis V, Gialamas I, Pediaditis E, Soundoulounaki S, Prinianakis G, Vaporidi K, et al. Validation of a proposed algorithm for assistance titration during proportional assist ventilation with loadadjustable gain factors. Respir Care 2020;65(1):36-44.

55. Carteaux G, Mancebo J, Mercat A, Dellamonica J, Richard JC, Aguirre-Bermeo $\mathrm{H}$, et al. Bedside adjustment of proportional assist ventilation to target a predefined range of respiratory effort. Crit Care Med 2013;41(9):2125-2132.

56. de Haro C, Magrans R, López-Aguilar J, Montanyà J, Lena E, Subirà $\mathrm{C}$, et al. Effects of sedatives and opioids on trigger and cycling asynchronies throughout mechanical ventilation: an observational study in a large dataset from critically ill patients. Crit Care 2019;23(1):245.

57. Gonzalez-Bermejo J, Janssens JP, Rabec C, Perrin C, Lofaso F, Langevin B, et al. Framework for patient-ventilator asynchrony during long-term non-invasive ventilation. Thorax 2019;74(7):715-717.

58. Hedden $\mathrm{H}$. The Accidental Taxonomist. Medford, New Jersey: Information Today; 2010.

59. Navarro-Sune X, Hudson AL, De Vico Fallani F, Martinerie J, Witon A, Pouget $\mathrm{P}$, et al. Riemannian geometry applied to detection of respiratory states from EEG signals: the basis for a brain-ventilator interface. IEEE Trans Biomed Eng 2017;64(5):1138-1148.

60. Becher T, van der Staay M, Schädler D, Frerichs I, Weiler N. Calculation of mechanical power for pressure-controlled ventilation. Intensive Care Med 2019;45(9):1321-1323.

61. Younes M. Proportional assist ventilation. In: Tobin M, editor. Principles and Practice of Mechanical Ventilation. New York: McGraw Hill; 2013:315-349. 